\title{
INMUNONUTRICIÓN REVISIÓn BIBLIOGRÁFICA
}

Por: Dra. Layne Quintero Graciela

Nutricionista Hospital Clínica Bíblica
Recibido: 20-11-19

Aceptado: 4-12-18 a nutrición y el sistema inmunológico están íntimamente relacionadas y sus respuestas en cada situación están condicionadas por cada un de ellos. Un paciente desnutrida presentará una disminución de la respuesta inmune ante las infecciones y por atra parte la respuesta inmunitaria a las infecciones conlleva producción de sustancias que tienen efectos metabólicos que aumentan los requerimientos nutricionales y por ende el estada nutricional del paciente.

En esta revisión Biblingráfica se toma como punto de partida a Chandra (I) y su definición sobre micronutrientes e inmunidad

1) Las alteraciones de la respuesta inmune se dan precozmente ante una reducción de la ingesta de nutrientes

2) La respuesta inmunitaria está relacionada con el tipo de nutriente implicada, si está a no en déficit y sus interacciones can otros nutrientes. Presencia de comorbilidades y edad del paciente.

3) Las pruebas de inmunocompetencia sirven para valorar las necesidades fisiológicas y los valores de seguridad de los micronutrientes

4) El aporte excesivo de micronutrientes, se asocia con pruebas inmunológicas alteradas

De tal manera que el debate gira alrededar de si la composición de la dieta afecta o no la respuesta metabólica e inflamatoria a las agresiones y puede incidir en la evolución del cuadro clínico del paciente.

El concepto actual de nutrir, bajo estas premisas, consiste en modular y hacer más específica la dieta de acuerda con la patología de cada paciente, en atras palabras, dietas individualizadas, diseñadas para cada procesa patológica. Es así como el concepto que conocíamos de nutriente como toda sustancia que se utiliza en el arganismo para obtener energía, construir y герагаг tejidas, se ha pasada al de inmunonutriente a nutrientes inmunamoduladares : Sustancia que a diferencia del nutriente convencional incide positivamente mejoranda la respuesta inmunitaria.

Durante los últimos 15 años se han realizada numerosos trabajos a сегса del soporte nutricional especializada, dirigidos a valorar las indicaciones de nutrientes inmunamoduladares, la mejor vía de aporte y los resultados obtenidas en cada casa, pero debida a la distinta metadalogía utilizada los resultadas abtenidas en las mismos san poco homagéneos y en algunas casos contradictorios.

Por tal motiva, la Sociedad Americana de Nutrición Enteral y Parenteral ha postulada las recomendaciones sobre su uso en la guias ASPEN 2002 (2), valorando estudios realizadas en pacientes can diferentes formulas comerciales especialmente diseñadas con adición de estos nutrientes bien sea una mezcla de ellos a el módula individual.

Las fórmulas actuales de inmunomoduladares cantienen básicamente glutamina, arginina, ácidas grasas amega-3 y nucleótidas (tabla l) los cuales en diferentes estudios han demostrada que acortan las días de estancia hospitalaria, disminuyen la incidencia de infecciones y reducen las costos hospitalarios en pacientes seleccionados. Los efectos son más consistentes en pacientes con trauma severo, incluidos los pacientes quemados, aquellos baju un procedimiento quirúrgico importante y de éstos, especialmente el paciente desnutrido previo al evento quirúrgico (3)

\section{Tabla 1. Principales compuestos con efecto inmunomodulador}

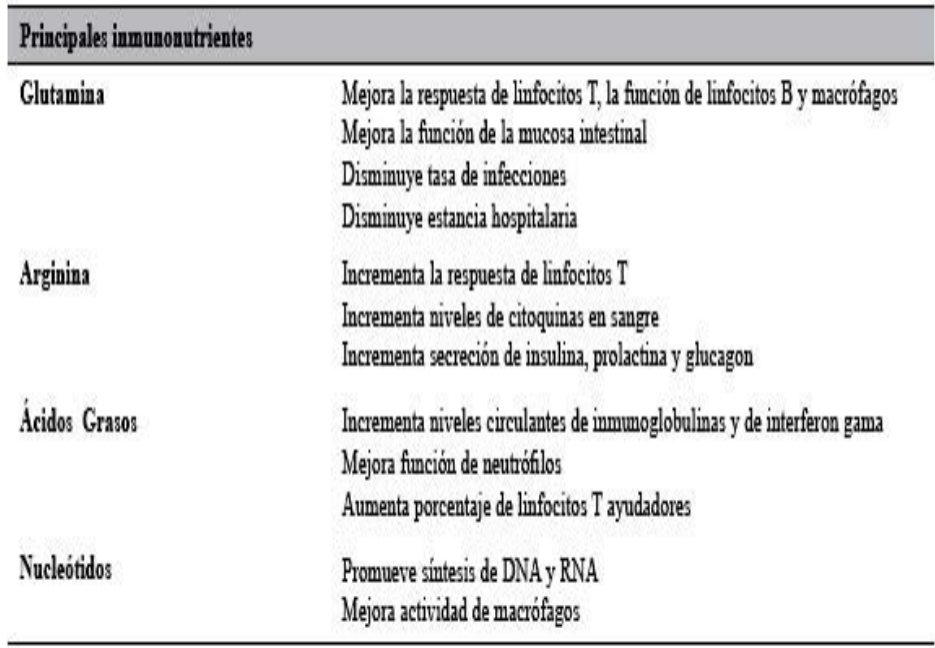

Glutamina

La glutamina es el aminoácido no esencial más abundante en el organismo jugando un papel importante en diferentes procesos metabólicos. Es un ргесursor de sustratos para la gluconengénesis hepática, es el combustible preferida por enterocitos y neutrófilos participando en las funciones de sistemas cama el gastraintestinal, inmunológica y muscular.

Durante la evolución de una enfermedad crítica, se ha demostrado una depleción impartante de las niveles séricas de glutamina convirtiéndase en un aminá́cido condicionalmente esencial, ya que los requerimientos del organismo durante un períado de estrés importante, sobrepasan la cantidad

de síntesis endógena (4.). La dasis eficiente de glutamina como suplemento debe ser de $0.5 \mathrm{~g} / \mathrm{kg} /$ día y administradas durante varios días. En las resultadas de diferentes estudias, se ha observada que existe una disminución en la incidencia de bacteremia en los pacientes a quienes se les administra glutamina (5) (6). En cuanto a la ruta de administración, se ha evidenciado en algunos reportes una mejor respuesta en la parenteral pero sin que la diferencia sea significativa. En los pacientes críticamente enfermos, hospitalizados en unidades de cuidado intensivo y que no pueden геcibir nutrición por vía enteral, la glutamina se debe administrar por medio de nutrición parenteral demostranda una reducción significativa en la marbilidad. Las dosis altas de glutamina, han demostrada mejorar la evolución de los enfermos en relación a las dasis bajas.

. La inmunonutrición en general y la administración de glutamina enteral en particular, han demostrada de forma consistente su papel benéfico en la población de pacientes quemados, en quienes las concentraciones de glutamina tanto musculares como plasmáticas son severamente depletadas. 
En esta población se ha demostrada que con la glutamina se previene la bacteremia y disminuye el índice de mortalidad.

Arginina

La arginina, de farma similar a la glutamina, es un aminaácida semiesencial que se convierte en esencial durante las situaciones hipermetabólicas y sépticas. La síntesis endágena de este aminaácida se ve superado por el incrementa en los requerimientos. Representa la mayor fuente de urea en el organismo, es necesaria para la síntesis de colágeno en la cicatrización de las heridas, modifica la inducción y desarrolla de tumares malignas a través de sus efectos sobre el sistema inmunológica, tiene capacidad de estimular la respuesta del timo, además favorece la liberación de diferentes hormonas como la hormona del crecimiento, insulina, glucagon, somatostatina, catecolaminas, aldasterona y vasapresina (7). El uso de arginina como inmunonutriente podría mejorar la respuesta de las células L y aumenta la fagacitosis. En pacientes postoperados de cáncer, suplementos de arginina, aumentan la respuesta de los linfacitos T a fitohemaglutinina y concavalina A e incrementan el número de linfacitos CD4. La arginina madula la respuesta inflamatoria e inmunológica. A pesar que se ha evidenciado una mejoría clínica en pacientes quirúrgicos, el beneficio de los pacientes en unidades de cuidada crítico con respuesta sistémica inflamatoria, sepsis y falla orgánica es menos claro. Al igual que sucede con la glutamina, la dosificación de la arginina es importante. No se ha demostrado beneficio con el usa de la arginina cuanda la concentración es menar a $6 \mathrm{~g} / \mathrm{L}$ de este aminaácida, pero concentraciones mayares de $12 \mathrm{~g} / \mathrm{L}$ han mostrada efectos favorables(7).

\section{Lipidas}

Los ácidas grasas presentes en la dieta tienen una función sobre el sistema inmune como sustrato y fuente energética a través de los ácidas grasos y las vitaminas liposolubles, además son un constituyente básico de las membranas celulares y modulan la síntesis de eicasanaides desde prostaglandinas, tramboxanos y leucotrienos hasta el factor agregante plaquetario (8)

La compasición lipídica de las células inmunológicas, es decir, de las monocitos, macrófagos, linfocitos y leucocitos polimorfanucleares, refleja la compasición de los ácidas grasas de los lípidas recibidas en la dieta. Las células del sistema inmune son capaces de sintetizar ácidos grasos no esenciales, рего dependen de las lípidas plasmáticas circulantes para obtener sus ácidas grasas esenciales. Son los productos del ácida araquidánico, los eicosanoides, los que tienen un efecto muy patente sobre la función inmunológica. Los ácidos grasos omega 6 son el sustrato básico en la farmación de ácida linoleica, que produce ácida araquidánica, favoreciendo la producción de metabolitos proinflamatorios, que finalmente afectan la respuesta inmune deteriorándala. La adición de ácidas grasas omega 3 limita este efecto proinflamatorio, éstos inhiben a las desaturasas G y 5 . La desaturasa 6 es la que principalmente limita la conversión de ácido linoleico a ácido araquidánico. Los ácidas grasos omega 3 , disminuyen la producción de citaquinas originadas del ácida araquidánica y suprimen la producción de interleuquina Z. Los ácidos grasos poliinsaturados suprimen la sensibilidad cutánea retardada. Los ácidas grasos omega 3 tienen efectos mixtos sobre la citataxicidad y mejoran la sensibilidad retardada (8)

\section{Vitaminas y elementos traza}

Aun no se conoce con certeza la cantidad de vitaminas y elementos traza que se requieren como suplemento ante diferentes agresiones. Se ha encontrado beneficio en pacientes críticamente enfermos con administración de elementas como vitaminas $A$, ᄃ, E, hierro, zinc y selenio con dosis que varían entre cinco y hasta veinticinco veces los requerimientos diarios, evidencianda elevación en los niveles séricas de dichos elementos. Los estudios realizados hasta ahora no han logrado definir la cantidad óptima de vitaminas y elementos traza para el tratamiento de pacientes sometidas a elevada estrés metabólica por cirugía, trauma o sepsis, aunque algunos estudios han demostrado un importante beneficio en pacientes críticamente enfermos.

\section{Ácidas nucleicas}

Las nucleótidas de la dieta pueden ser necesarios para mantener la función inmunológica normal. La hipersensibilidad cutánea retardada, la proliferación linfocítica estimulada por mitógenos, el rechazo de injertas, y la enfermedad del huésped frente a un injerto, se suprimen con una dieta sin nucleótidas22. Añadir ARN a la dieta, previene la inmuno-supresión. № proporcionar nucleótidas suprime de manera selectiva las células L-ayudadaras y la producción de IL-Z. El suplemento de la dieta, con ARN a con bases pirimidínicas, talvez sea necesario para mejorar la supervivencia frente a la agresividad bacteriana y para mantener una función inmunitaria normal. Su aporte en la dieta restaura la anergia

cutánea, revierte la inmunosupresión secundaria a la transfusión, disminuye también la formación de abscesos por gramnegativos en peritonitis y mejora la actividad de macrófagas mediada por linfacitas T. La función básica de las nucleótidas es ser parte fundamental de la síntesis de RNA y de DNA para los compuestas transportadores de energía. Lo cual explica teóricamente su función en el mejoramienta de la respuesta inmune. Se puede concluir que el aporte óptimo de nucleótidos mejora la función de las células, sobre todo las de reproducción rápida, y que su deficiencia reduce la función inmunológica, рего hasta ahora ningún estudio ha mostrado que la adición de nucleótidos a la dieta sea benéfica.

\section{Conclusiones}

Los beneficios de las dietas inmunamoduladaras han sida demostradas en pacientes politraumatizados y quirúrgicos, sin embargo, no se ha podido demostrar fehacientemente que los costas de su utilización justifiquen su usa. Hasta el momenta, la mejora en la función del sistema inmunalógica mediante el usa de este tipo de dietas, ha demastrado que disminuye las días de estancia y las complicaciones infecciosas; lo cual implicaría la disminución de las costas de atención. La regulación de la respuesta inflamataria a las agresiones y a la infección, es una de las abjetivas principales del manejo de los pacientes con patolagía quirúrgica, trauma y cáncer.

En la actualidad el concepto de inmunonutrición e inmunamodulación es una alternativa llamativa que abre una nueva dimensión en el manejo de pacientes y la nutrición moderna.

\section{REFERENCIAS:}

I.Grimble R. Basics in clinical nutrition: Immunonutrition-Nutrients which influence immunity: Effect and mechanism of action. Eur ل I Clin Nutr and Metabolism 2009; 4: I0-13. Dispanible en: www.sciencedirect.com (Consultado el 30 de Abril de 2009).

2.Klek S, Kulig ل, Sierzega M, Szzzepanek K, Szybinski P. Walewska E, et al. Standard and immunomodulating enteral nutrition in patients after extended gastraintestinal surgery-A prospective, randamized, controlled clinical trial. Clin Nutr 2008; 27: 504-512. Disponible en: http://www.sciencedirect.com/ (Consultada el 30 de Abril de 2009)

3.Calder P. Immunonutrition in surgical and critically ill patients. Br J Nutr 2007; 98 Suppl I: SI33-139

4.Kreymann G. Early nutrition support in critical care: a European perspective. Curr Dpin Clin Nutr Metab Care 2008; 11: 156-159

5.Bistrian B. McCowen K. Nutritional and metabolic support in the adult intensive care unit: Key contraversies. Crit Care Med 2006; 34: 1525-1531
6.Montejo ل, Zarazaga A, López J, Urrutia G, Roque M. Blesa A, et al. Imunnonutrition in the intensive care unit. A systematic review and consensus statement. Clin Nutr 2003; 2Z: 2Z1-233. Dispanible en: http:// www.sciencedirect.com/ (Consultado el 30 de Abril de 2009)

7.Stahel P. Smith W. Moore E. Role of biological modifiers regulating the immune response after trauma Injury Int ل Care Injured 2007; 38: 1409-1422. Disponible en: www.elsevier.com (Consultado el I0 de Abril de 2009).

8.Stableforth W. Thomas S, Lewis S. A systematic review of the role of immunonutrition in patients undergoing surgery for head and neck cancer. Int. J Oral Maxillofac Surg 2009; 38: 103-1ID. Dispanible en: http://www.sciencedirect.com/ (Consultada el I0 de Abril de 2008). 